\title{
Genealogy of Polish Melancholy Commentary to Mira Marcinów's Book The History of Polish Madness
}

\author{
Andrzej Kapusta \\ Maria Curie-Skłodowska University, Lublin, Poland \\ andrzej.kapusta@poczta.umcs.lublin.pl
}

Received 22 February 2019; accepted 17 April 2019; published 12 December 2019

\begin{abstract}
The purpose of this article is to indicate the specificity and difficulties of the project of writing the History of Polish Madness presented by Mira Marcinów. Marcinów goes beyond the area of the traditional history of psychiatry and notices in the material she researched the chance to trace the genealogy of Polish madness. The task of the genealogical approach is to make history that will challenge the obviousness and validity of our understanding of a specific area of human experience, in this place of madness. The author of the article wonders to what extent the project of genealogy of madness is a successful project.
\end{abstract}

Keywords: history of psychiatry; madness; melancholy; genealogy; Mira Marcinów.

The history of psychiatry is the area of dispute about the nature of psychiatry and mental disorders, the source of considerations on how to treat historical documents, and more broadly the place of disputes about our attitude to the past. The area of psychopathology is inevitably embedded in social and cultural ideas about it. Diagnosis of mental illness cannot be easily separated from social beliefs and cultural assumptions of a given epoch. The purpose of this commentary is to indicate the specificity and difficulties of the project of writing the History of Polish Madness presented by Mira Marcinów. What is the meaning and what is the potential impact of selected historical documents on contemporary psychopathology. To whom are these analyses addressed? Marcinów goes beyond the area of the traditional history of psychiatry and notices in the material she researched the chance to trace the genealogy of Polish madness. In what sense this is a genealogical project and what are its potential effects? Generally speaking, genealogy is an attempt to reconstruct 
and identify key moments in the history of our thinking and action, while at the same time trying to question the obviousness and unquestionability of the assumptions. In a similar way, Marcinów refers in critical way to the $19^{\text {th }}$ century history of Polish madness. So it is not just a history of science and medicine, but also a philosophical attempt to go beyond a simple fact finding.

Reaching to the period of psychiatry and psychopathology in Poland at the end of the nineteenth century does not tell us much about the national local way of practising psychopathology in the form of a characteristic style of thinking, paradigm or school. Perhaps this is why the ways of thinking about ourselves, our identity, sexuality, normality, corporeality in the context and the area of Polish mentality and Polish language are clearly revealed to us. Sensitivity to social and cultural issues becomes especially possible, because the $19^{\text {th }}$ century is for psychiatry the moment of shaping it as an independent and relatively stable field. It is also a period of transformation of morals and shaping the social or national identity of Poles. That is why the author expresses the hope that the documents may say much less about the madness and aberrations of the human soul than the way we think about our identity in relation to extreme situations and experiences.

The lack of a clearly shared psychiatric doctrine or school in the Polish lands causes that we try to search in presented texts for the moments of local perception of Western thought and the involvement of primary scientific and objective ideas into local socio-cultural conditions. The selection of documents proposed by the author gives us a general picture of discourses about the local psychiatry and attitude to mental disorders in the nineteenth century Poland. Contrary to the title of the book, which suggests the presence of texts dedicated to melancholy and depression, we have many texts devoted to hysteria, caselaw and reflection on the state of hospitality and the functioning of the care system.

Mira Marcinów project is impressive and very ambitious in its assumptions because she not only undertakes the work of a medical historian and the researcher of intellectual history of Polish medical and philosophical society, but also wants to offer a cultural diagnosis of contemporary Polish soul. The author is aware of the difficulty of writing about psychological determinants of mental health in the era of shaping the foundations of scientific psychology and psychiatry. First of all, she would like to prepare the reader for the encounter with $19^{\text {th }}$ century Polish psychopathological literature, and hopes that carefully selected texts evoke astonishment as bizarre stories and anecdotes extracted from psychiatric archives and expressed in a rather old-fashioned language. Thoughts and statements published and presented by Polish psychiatrists may seem difficult to locate and assign in the wider context of Western psychiatry. The "secondary" and "lost" stories can only seem to be a secondary reflections of the thoughts and discoveries of Western psychopathology. However, Marcinów would like to convince us that they are worth investigating, rethinking and digesting. As an urgent student referring to the achievements of Michel Foucault, a French historian and philosopher of madness, she notices the transformative power of local and forgotten discourses. Like a genealogist, she would like to find traces of the present in the texts from the past unknown to the wider audience. The author seems to share the view 
regarding the relationship of madness with social values, as we find in a Catalan psychiatrist of the nineteenth century, Gine y Partagas: "human knowledge reflects the moral and political development of the nations; the best example of this is that branch of medicine that deals with mental illness" (see Berrios, 1996, p. 8). However, she does not believe in the unambiguous progress of our self-knowledge and, to a large extent, inclines to the revising version of the history of psychiatry, which is accompanied not so much by the metaphor of the clinician as cataloguing plants in a garden, but by the metaphor of a sculptor carving out of formless matter, i.e. creating "clinical forms" (constructionism).

The book reveals the richness of forgotten clinical descriptions of madness. The positive work of Marcinów is manifested in the attempt to order the wealth of a diverse and often incoherent material based on the classification of mental phenomena proposed by the historian of modern psychiatry G. E. Berrios (on the cognitive, emotional, volitional and personality aspects). The analysis of representative Polish documents and textbooks that were created at the end of the $19^{\text {th }}$ century allows the isolation and clinical evaluation of melancholy at that time, the search for methods of diagnosis, the indication of aetiology and the proposed treatment. The author is aware that her effort is provisional and does not meet a strict criteria of reliable clinical evaluation. We are dealing with a specific research material, because the proposed documents of Polish psychiatry were created on various occasions in various centres. However, this does not prevent us from getting a general idea about expert thinking about melancholy, its symptoms, causes and types of treatment. Systematisation taken by the author seems to be the most clearest, most-ordered part of the book. It is an attempt to inscribe melancholy into the frame of clinical thinking. At the same time, comments and commentaries to selected source materials show the richness of the discussed topics and a certain surplus of content that is not easily included in the proposed clinical research framework. The effect of this systematization is not the "calibration of psychopathology" from historical, clinical and numerical perspectives (see Berrios, 1996).

Among the symptoms of Polish melancholy at the end of the $19^{\text {th }}$ century, cognitive changes are on the forefront: intellectual slowness, degradation of the cognitive sphere, hallucinations, delusions. Then, emotional sphere disturbances: sadness, fear, longing and changes in behaviour: lack of movement, immobility, inability to act (with the possibility of fits of rage-raptus melancholicus), sleep and appetite disorders and suicidal thoughts. The exposure of behavioural and volitional factors in psychopathological descriptions and diagnoses at the expense of affective elements is probably related to the easier availability of this type of data. In turn, the rarity of recognizing personality changes in the form of a taste for solitude or suspiciousness is explained by the author with a short history of the knowledge about personality disorders (paradoxically, the patients' frequent perception of character defects).

It is more difficult to diagnose the causes (aetiology) of nineteenth century melancholy. The psychological reasons are most easily indicated in the form of unpleasant events that precede (triggers) the appearance of melancholy. It is often pointed to wounded self-love, lack of social support. These factors are independent of the patient. However, those that are in a 
sense dependent on him often refer to his lifestyle: for example, a sedentary lifestyle, dedication to science (scientific work, study), "badly" understood religiosity, devotion to worries and autoeroticism. A separate place is occupied with excessive alcohol consumption.

Therapeutic effects on melancholy can be divided into psychological / moral and somatic / physical. In the first case, persuasion (moral therapy) becomes dominant as a kind of instructing the patient about the need to change behaviour and a conversation that could take a form similar to psychotherapy. It is quite obvious to combine therapy with knowledge of the causes of psychopathology. Therefore, the break with pathogenic habits (e.g., not sleeping) had a clearly curative character. Seemingly biological therapies in the form of wrapping the patient into warm blankets or elements of hydrotherapy ultimately had a psychological character. A commonly used somatic medicinal agent was poppy-seed cake (opium) as a mitigating melancholic suffering. Dietary change or even electrotherapy was also used. Marcinów emphasizes a certain dynamics of changes in healing methods in the mid-nineteenth century, which is manifested by the more frequent use of psychological agents (e.g., allowing the patient to experience emotional states of despair emotionally).

Organizing the historical clinical material is always a somewhat arbitrary choice. To the expert on mental health issues, the clinical thought about melancholy may seem naive and somewhat trivial. Are we not in another place today with our knowledge of neurobiology, psychopharmacology and modern therapeutic communities? Reaching historical texts may change our thinking about madness, but faith in the power of historical texts is always fragile and uncertain. We know, however, that human dramatic stories can trigger a social imagination, which is exemplified by the figure of van Gogh or Artaud. At the same time, the author notices a dilemma in a madness, the resolution of which also constitutes the contemporary problematization in the area of mental health. What is the madman's subjectivity about? Is it possible for him to voluntarily surrender, devote himself to madness?

In historical texts and expert statements, we are not looking for the truth about depression. Thanks to our distance from nineteenth-century thinking, it is easier to see its attachment to that place and that era. So what can we discover in these statements and comments? What can surprise us and make us amazed? One thing is certain, lesser known and forgotten documents were published in medical journals, textbooks, and newspapers addressed to medical specialists. The author does not reach for embarrassing hospital regulations, codes. We also do not find the statements of the patients themselves, the "diary of my mental illness," the confidences and concerns of their relatives (We do not know if such polish "psychiatric" documents have not yet been discovered, and whether there are any hidden ones in the archives). Traces of more subjective and expressive voices of madness Marcinów try to look for in literary works. As if literature and art would be easier to reach our sensitivity and imagination.

In the documents attached to the book, we see moments of misery, violence, human unhappiness and injustice. The descriptions of women's hysteria, motherly judgments, and deviant behaviours are particularly striking. Reading these passages, we can wonder how our sensibility about social norms and behaviours has changed. The author struggles with 
the ambitious task of cultivating a genealogy of madness / melancholy. She is afraid of entering her statements into a "discourse of power-knowledge" (p. 211), that is, creating a "correct" model of madness, distinguishing its truth in the discussed era, but the truth hidden under historical discourse. That is why she wonders whether it is possible to "doubt" the "naturalness" of depression (p. 211).

Marcinów is particularly interested in what gives expression in her commentaries, the problem of agency (subjectivity) of the melancholy. She says: "I was interested in thinking on the margins of the discovered texts of what is the gesture of (pseudo) voluntary entry into madness and melancholy awareness of the unattainability of control over madness" (p. 211). What can be interpreted as the possibility of seeking the agency of your own melancholy, at the same time getting caught up in it and getting lost in it. Are we dealing today with a return to such a thinking? Do we want to blame the madman for his madness? Are we looking for moments of his wrong decisions, as it was done to the criminal and the child-victim? The prospect of looking for the madman's subjectivity may initiate such subjectivity, and we must listen to his voice, wait for his experience and prescription. This type of transformational subjectivity is more possible in relation to collective subjectivity, in reference to social resources and support of a person in a crisis. The presented documents do not have this perspective. The patient is basically the object of classification, diagnosis of treatment, judgment.

The problem of the subjectivity of the madman, his or her ability to get stuck in insanity seems to be a key dilemma whose resolution leads to different concepts of psychiatry and psychopathology. Can it be so easily extracted from these historical texts? We will find out more quickly about the concept of madness recognized by doctors and people belonging to those times.

The great advantage of the conducted analyses is the awareness of contemporary transformations and changes in the understanding of psychopathological phenomena shown in the comments and definitions of the described cases. There are also frequent comments about gender and attribution to women of a specific type of disorder. The richness of the presented material is the result of the activity of clinicians of various schools and influences (Warsaw, Vilnius, Cracow). Is it possible, however, to distinguish the zone of relations and dependencies between schools, or do expressive styles of thinking and paradigms appear? The author only signals these issues because she is essentially interested in something else.

She recognizes in the language of melancholy a certain surplus which not only determines the states and transformations of individuals, but allows us to look at the whole community. It is not only about the psychopathology of individuals, but about diagnosing the condition of the Polish soul, searching for the Polish Saudade. To better describe the poetics of Polish culture, the author reaches for the Polish literature of this period. She finds traces of melancholy in the writings of Słowacki, Mickiewicz and Krasiński (melancholy as "the sun in the black sky"). Perhaps literary language (including the language of literary studies) is able to better grasp what in the language of clinical melancholy only smiles. 
The researcher is following the trail we encountered in Michel Foucault's History of Madness. Archaeology of melancholy requires reaching for the non-medical archive, "breaking the corset of medicine" (p. 201). Just like Louis Sass in Madness and Modernism (Sass, 1994, and even Freud, Jung and Fromm earlier), the author sees the possibility of looking at the local melancholy identity through the language of our psychopathology. Not only art and culture allow us to better understand melancholy and depression, but it is the melancholy itself, the type of appropriately used psychopathological tools and metaphors that better understand and shape our condition.

Ultimately, the basic core of the book is not the author's interpretations and comments, but an appropriate selection of sources for the history of nineteenth-century madness in Poland. It is not known until the end how the reader is to deal with these texts. He can read them as anecdotal descriptions of cases of melancholy, he can also adequately armed with the theoretical tools of the earlier chapters of the book to discover the regularities and orders presented there. At the end, Marcinów secretive hope appears that the texts themselves will speak to us and let us look at them as if in a distorting mirror.

So what is the genealogical approach of Mira Marcinów? The task of the genealogical approach is to make history that will challenge the obviousness and validity of our understanding of a specific area of human experience, in this place of madness. Which will force us to think differently about ourselves, to make us look for other self-definitions. The author directly asks the Polish reader to make a cultural self-diagnosis by reading the book. First of all, it extracts and makes available forgotten documents, in this way collides our sensitivity with a different language. This is particularly evident at the level of access to the language of psychopathology, which is anchored in Polish meanings and words, and not in technical and medical-scientific terminology. The author is also interested in the problem of subjectivity, something that can be defined as the genealogy of a modern subject. Perhaps in extreme borderline and marginal cases, specific experiences and dimensions of subjectivity are revealed. The analysis of the ways of diagnosing and treating Polish melancholy is also a practical implementation of a certain concept of ourselves. A madman, a stranger is a kind of reflection of ourselves. The third element of the genealogy is a transgressive, ironic or aesthetic moment. It consists in shifting the considerations and studies from the area of defined psychopathology to the area of our cultural and national identity. The result of these operations may be defamiliarization of these historical texts and a different look on them. This required additional access by the author to a wider historical archive. First of all, for literary sources that in their lyrical language can activate our cultural imagination. The genealogical theme is present in the author's self-commentary on the intentions and aims of her own project. We are dealing with the suggestion that this is not just a story written by a historian of science.

Is the proposed genealogy project satisfactory? It is not completely full and consistent. Elements of genealogical thinking are partially created in the margins of research conducted by the author. They are only outlined and, to a large extent, have a declarative and provisional character. We are dealing with documents that the author is discussing and 
systematizing. However, they are essentially medical discourses that reveal their moralistic and cultural character in relation to psychopathology. It was probably difficult to find records in the Polish $19^{\text {th }}$-century archive, the authors of which would be the patients themselves or individuals critical of institutional psychiatry. There were no papers that would escape the order of the medical discourse. Also in the literature and Polish art of this period there were no such strong individuals at the same time involved in the discourse of psychiatry, such as van Gogh, Artaud, Nietzsche. There was also no set of statements and comments similar to the one published by Foucault: I, Pierre Rivière, Having Slaughtered My Mother, My Sister, and My Brother... (Foucault, 1975). The book contains an extensive collection of historical documents. It seems, however, that even a small collection of selected documents revealing the social, cultural or political context of psychiatric practice and a more critical commentary would allow to unmask one-sidedness and morally doubtful involvement of medical discourse and make it easier to achieve a more transforming effect. Hope of the author of Polish Madness that "my countrymen" look at the proposed documents as a mirror seems to be an excessive expectation, a kind of secretive desire of the author, which to bring the intended effect must would have to fall on a particularly fertile ground.

\section{References}

Berrios, G. E. (1996). The History of Mental Symptoms. Descriptive Psychopathology since the Nineteenth Century. Cambridge, UK: Cambridge University Press.

Foucault, M. (1975). I, Pierre Rivière, Having Slaughtered My Mother, My Sister, and My Brother. New York, NY: Pantheon Books.

Sass, L. A. (1994). Madness and Modernism: Insanity in the Light of Modern Art, Literature and Thought. Cambridge, MA: Harvard University Press.

The editorial and publishing process of this publication has been financed by the Ministry of Science and Higher Education from the funds for the dissemination of research (DUN) within the framework of publishing activity, contract no. 711/P-DUN/2019, period of implementation: the years 2019-2020. 